\title{
Public Health Impacts of Exposure to Disinfectants, Therapeutics, and Illicit Substances During the COVID-19 Pandemic
}

\section{COVID-19 Pandemisi Sırasında Dezenfektan, Terapötik ve Yasadışı Maddelere Maruziyetin Halk Sağlığına Etkileri}

Elif Çisem Çöldür ${ }^{1}$

ORCID: 0000-0003-3522-9617

Rengin Reis ${ }^{2 *}$

ORCID: 0000-0002-3484-2201

\begin{abstract}
${ }^{1}$ Akdeniz University, Department of Gene and Cell Therapy, Antalya/ TURKEY.
\end{abstract}

${ }^{2}$ Acibadem Mehmet Ali Aydinlar University Faculty of Pharmacy, Department of Toxicology, Atasehir, Istanbul/TURKEY.

Corresponding author:

Rengin Reis

Acibadem Mehmet Ali Aydinlar University Faculty of Pharmacy, Department of Toxicology, Atasehir, Istanbul/ TURKEY.

E-mail: rengin.reis@acibadem.edu.tr Tel: 02165004444 / 4259
DOI: 10.52794/hujpharm.978727

\section{ABSTRACT}

The SARS-CoV-2 virus spread rapidly, infecting over a hundred million people worldwide; thus, it has been called the COVID-19 pandemic, in which it is very important to wear a protective mask, wash hands properly, obey social distance rules, and use disinfectants to protect ourselves against infection. Therefore, the consumption of cleaning agents such as disinfectants, surface cleaners, and bleach has increased during the pandemic. Misuse of these substances such as drinking or gargling of cleaners and excessive use has led to many poisoning cases and even deaths. In addition, quarantine and stay-at-home orders during the pandemic caused people to could not socialize and feel dissociated. Moreover, due to the economic problems, many people became unemployed, which affected substance abuse and alcohol consumption frequency, thus poisoning cases as well. This article aimed to review how the COVID-19 was affected the disinfectant or cleaner-induced poisoning cases and the public health impacts between the drug or substance abuse due to pandemic.

Keywords: SARS-CoV-2, alcohol-poisoning, hand sanitizers, substance abuse, drug misusage

\section{ÖZET}

SARS-CoV-2 virüsü hızlı bir şekilde yayılarak dünya çapında yüz milyonun üzerinde insanı enfekte etmiş; bu nedenle COVID-19 pandemisi olarak adlandırılırken, hastalığa yakalanmamak ve virüsten korunmak için maske takmak, sosyal mesafe kurallarına uymak, elleri doğru şekilde sık sık yıkamak, dezenfektan kullanmak büyük önem kazanmıştır. Bu nedenle dezenfektan, yüzey temizleyiciler ve çamaşır suyu gibi temizlik maddelerinin tüketimi pandemi süresince artmıştır. $\mathrm{Bu}$ maddelerin içilmesi/ gargara yapılması veya aşırı miktarlarda kullanımı yanlış kullanımı birçok zehirlenme vakasına ve hatta ölümlere sebep olmuştur. Buna ek olarak, pandemi süresince yapılan karantina uygulamaları insanların sosyalleşememesine ve kendilerini soyutlanmış hissetmelerine neden olmuştur. Ayrıca, ekonomik sorunlar nedeniyle birçok kişinin işsiz kalması, madde bağımlılı̆̆ 1 ve alkol kullanım sıklığını etkileyerek zehirlenme vakalarını da beraberinde getirmiştir. Bu derleme, COVID-19'un dezenfektan veya temizleyici kaynaklı zehirlenme vakalarını nasıl etkilediğini ve pandemi sebebiyle ortaya çıkan ilaç veya madde suistimalinin halk sağlığı üzerindeki etkilerini derlemeyi amaçlamaktadır. Anahtar kelimeler: SARS-CoV-2, alkol zehirlenmesi, el dezenfektanları, madde suistimali, yanlış ilaç kullanımı 


\section{INTRODUCTION}

Coronavirus disease 2019 (COVID-19), is the pandemic firstly reported in 2019 in Wuhan, Hubei province, China, and caused by the SARS-CoV-2 virus [1]which reported in an outbreak in 2019 in Wuhan, Hubei province, China, is caused by the SARS$\mathrm{CoV}-2$ virus. The virus belongs to the beta-coronavirus class, along with the Middle East Respiratory Syndrome coronavirus and Severe Acute Respiratory Syndrome coronavirus. Interestingly, the virus binds with angiotensin-converting enzyme-2 found in host cells, through the spike ( $\mathrm{S}$. The responsible coronaviruses are a member of single-stranded RNA viruses [2], which are small-sized and single-stranded RNA viruses that are ranging from 65 to $125 \mathrm{~nm}$ $[3,4]$ the identification of the coronavirus responsible for the outbreak of severe acute respiratory syndrome showed that highly pathogenic coronaviruses can enter the human population. Shortly thereafter, in Holland in 2004, another novel human coronavirus (HCoV-NL63. Coronaviruses can infect animals and humans thus; they can infect humans are named human coronavirus ( $\mathrm{HCoV})$. The first reported case of SARS-CoV-2 was seen in Wuhan city of China in the end of 2019 with an unknown etiology and the initiation of the outbreak was thought to be due to the consumption of different kind of animals such as bats, snakes, frogs and birds from Hunan seafood market as food [4]. However, follow-up studies confirmed that SARS-CoV-2 have an ability to pass through aerosol among individuals [4,5]. Following the simultaneous studies on the identification of COVID-19 etiology and epidemiology, prevention methods against SARS-CoV-2 has gained attention through the hygiene rules particularly based on hand washing, protective mask-wearing and maintaining at least one-meter distance among individuals according to the latest protocol of WHO [6]. In addition to these hygiene protocols and preventive care, remdesivir has become the first Food and Drug Administration (FDA) approved drug in the treatment of COVID-19 [7]. Oseltamivir, Favipiravir and Lopinavir/Ritonavir are used in treatment protocols in Turkey according to a decision on 22 July 2020 of Republic of Turkey Ministry of Health [8]. In addition to the aforementioned treatment protocols, simultaneous vaccine studies in clinical development are available for above sixty vaccines and 173 vaccines are also in pre-clinical development ac- cording to the latest report of WHO in March 2021, as well [9]. From the second half of January 2021, COVID-19 vaccines developed by Pfizer-BioNTech, Moderna, Astra Zeneca's, Jansenn, Novavax and Sinovac companies are available [10] and the CoronaVac vaccine by Sinovac has been used in Turkey since January 13, 2021.

Although the drug and vaccine studies against COVID-19 are still under development, strict social distancing and hygiene rules were the fundamental elements for the prevention and spread of disease, as well. Based on this purpose, people have been using disinfectants, cleaners and specific drugs/ supplementary medicines to avoid COVID-19 disease since the beginning of the pandemic. However, increased exposure frequency and misusage of these wide-scaled products have been causing a noteworthy concern in poisoning cases during the COVID-19 pandemic [11-14]the Croatian Poison Control Centre started receiving phone calls from the general public and healthcare workers, which prompted us to investigate whether the risk of suspected/symptomatic poisonings with disinfectants and sanitisers really increased. To that end we compared their frequency and characteristics in the first half of 2019 and 2020. Cases of exposures to disinfectants doubled in the first half of 2020 (41 vs 21 cases in 2019. In addition, the tendency to drug abuse has increased due to the social-psychological situation being negatively affected during COVID-19. 25\% increase in drug abuse is identified in pandemic due to emotional changes that consist of feeling fear, worry, sadness and loneliness [15-17].

Therefore, the present review aims to highlight the misusage of drugs used for symptomatic relief as well as cleaners, household products, and disinfectants for the prevention of infection during the COVID-19 pandemic by evaluating up-to-date reports in early 2020 to mid-2021.

\section{DISINFECTANT USE and STERILIZATION IN COVID-19}

\subsection{Hand sanitizers}

Ethanol is one of the primary alcohols that has antiseptic properties and it consist of two carbon, six hydrogens and one oxygen atom [18]. Due to its antiseptic property, ethyl alcohol is the main ingredient 
of disinfectants such as hand sanitizers and surface cleaners [19]. Ingestion of large quantities of ethanol such in the form of alcoholic beverages, mouthwash or cologne might cause nausea, vomiting, amnesia hypothermia, dysarthria and even death, which was seen after respiratory depression and coma. About 3 million deaths caused by alcohol are reported in the United States [20]. Hand sanitizers are formed by ethanol, chlorhexidine and isopropanol as $70-80 \%$, $<5 \%$ and $10-100 \%$, respectively. These ingredients had the potential to cause mucous membranes irritation either by dermal contact or inhalation and frequent and intensive use might result in systemic alcohol toxicity [13]. After the COVID-19 outbreak, the usage of hand sanitizers that should contain ethanol or isopropyl alcohol about $75-80 \%$ according to WHO was increased to prevent any virus, mainly coronavirus, related infection. Systemic toxicity in minimal levels by dermal contact or ingestion of hand sanitizers has been known Although ethanol toxicity that is caused by hand rub or dermal contact cannot be degreed due to tolerance of ethanol differs from person to person [12] the Croatian Poison Control Centre started receiving phone calls from the general public and healthcare workers, which prompted us to investigate whether the risk of suspected/symptomatic poisonings with disinfectants and sanitisers really increased. To that end we compared their frequency and characteristics in the first half of 2019 and 2020. Cases of exposures to disinfectants doubled in the first half of 2020 (41 vs 21 cases in 2019). Hand sanitizers can attract children because of their scent and packaging and thus, the children might be under the risk of alcohol poisoning by ingesting these attractively packaged hand sanitizers [12,21] the Croatian Poison Control Centre started receiving phone calls from the general public and healthcare workers, which prompted us to investigate whether the risk of suspected/symptomatic poisonings with disinfectants and sanitisers really increased. To that end we compared their frequency and characteristics in the first half of 2019 and 2020. Cases of exposures to disinfectants doubled in the first half of 2020 (41 vs 21 cases in 2019. In parallel, about 24,000 children under the age of 12 years old were suffered from ethanol toxicity during 2020 with a peak number on March nearly 2500 cases according to a report of the American Association of Poison Control Center which published on December 31, 2020 [22]. The toxicity cases due to hand sanitizer exposure were observed most commonly in pre-school-aged chil- dren according to a report of Croatian Poison Control Center [12]the Croatian Poison Control Centre started receiving phone calls from the general public and healthcare workers, which prompted us to investigate whether the risk of suspected/symptomatic poisonings with disinfectants and sanitisers really increased. To that end we compared their frequency and characteristics in the first half of 2019 and 2020. Cases of exposures to disinfectants doubled in the first half of 2020 (41 vs 21 cases in 2019. A recent report by Chang and colleagues indicated that ingestion of ethanol-based hand sanitizer approximately as 2 liters by pre-school aged children caused by dizziness as a systemic toxicity symptom [23]. In addition, number of hand sanitizer exposure cases in children is increased in early five months of 2020 and peak number is recorded in March, 2020 which is more than 2000 cases [22].

\subsection{Cleaners and disinfectants}

Disinfectants can be described as chemicals that kill a wide range of microorganisms such as viruses and bacteria compared to sanitizers [24]. In addition, hand sanitizers are the products of choice when there is no opportunity to wash hands to reduce the number of bacteria to a safe level [25]. Cleaners are used to remove organic matters and dirt from surfaces like detergents and soaps [24]. WHO published different cleaning protocols for healthcare setting environments and non-health-care setting environments that included initially removing organic matter by cleaning surfaces with detergent or soap followed by disinfection process [26]. Additionally, many pieces of advices are included on the WHO website for the public to prevent COVID-19. For example, cleaning protocols like how to wash hands properly are explained in a very detailed way with cards. Due to disinfection and cleaning become an important part of human life with SARS-CoV-2 pandemic, about three of five people increase the frequency of disinfection period in their daily life. Cleaning products and disinfectants contain mainly quaternary ammonium compounds (QACs) that can be caused to breathing problems, pulmonary damage and a rise in asthma triggers. Therefore, a rise in poisoning calls related to increasing frequency and amount of exposure to cleaning products and disinfectants at home or work are reported. [27] Furthermore, poisoning calls related to cleaners generate more than $60 \%$ of all exposure calls which is about 45,500 cases in to- 
tal according to the report of the Centers for Disease Control and Prevention (CDC) between January and March 2020. On the other hand, calls caused by disinfectants are consist of about $38 \%$ of all exposure calls which increase about $16 \%$ compared to the same period of 2019. The peak of exposure caused by cleaners and disinfectants was observed nearly in the first days of March 2020 [23]. According to further analysis, cases caused by non-alcoholic disinfectants increase by nearly $36 \%$ which is lesser than cases caused by bleach approximately $60 \%$. When exposure routes are compared, inhalation takes the largest percentage of increase among 2019 to 2020 in all routes. Another data according to this report is that calls for children under five years old constitute the largest part of the total calls between nearly $40-50 \%$ [23]. Another report was published from a healthcare network in Philadelphia that highlights increase in pediatric poisoning during the COVID-19 pandemic mainly March to May 2020. According to this report, due to staying for long times in houses, increase cases of poisoning in children especially six to twelve was observed when compared to data of 2019 at the same time. All pediatric cases that included only less than 18 years old were evaluated which are get from American Association Poison Control Center Data System [28] the virus responsible for the illness "'COVID-19,", was announced by China in December 2019. Soon after, a pandemic was declared by the World Health Organization (WHO. One of five increases of exposure to cleaners and disinfectants is reported in poison centers in the US between January and March of 2020 and significant rise has occurred in disinfectant calls nearly as $16 \%$. All calls for cleaners and disinfectants through April 2020 for Michigan Poison Center are examined in a report and about $40 \%$ of the increase is detected in disinfectant calls. A third of five increase is also observed in disinfectant calls with symptoms and the proportion of disinfectant calls constitutes more than half of all calls. After the first COVID-19 case is seen in Michigan, the number of calls to MiPC doubled per day comparing to 2019. However, increase of the number of calls for cleaners is not as much as the number of disinfectant calls. Moreover, there is no significant variation between 2020 and 2019 calls for cleaners about $5.5 \%$ to $5 \%$, respectively. The number of the caller with symptoms that include allergic rhinitis, asthma and other respiratory problems is increased about $10 \%$ when comparing to the first three months of 2019 and 2020. In addition, the number of disinfectant exposure cases are increased among children under 5 years old by inhalation. [14]. Retrospective analyses about exposures in France during COVID-19 were done by French Poison Control Centers. Analyses revealed that the number of disinfectant exposure calls increased mainly in March and April 2020. Moreover, disinfectant exposure calls were reported more than hand sanitizers. The cause of some disinfectant exposures was reported that patients put disinfectants into water to clean their vegetables. They also reported that elderly people like $>65$ years old were affected more than other age groups [29]2019, and 2020 were extracted from the French National Database of Poisonings. The collected data included call, patient, and exposure characteristics for both general calls and for calls involving sentinel xenobiotic categories related to the COVID-19 pandemic. The 2020 exposures were compared to 2018-2019 exposures by using simple logistic models in order to provide effect size with odds ratios. From March to April 2020, 32,182 exposures were reported to French PCCs with an overall increase of $5.6 \%$ compared to exposures in the same time frame in 2018-2019. A similar increase in calls was observed in non-epidemic and epidemic COVID-19 areas with an increase in calls from the public $(+13.6 \%)$.

A report published on April 24, 2020 highlights the exposure of chlorine that comes up with mixing bleach and other cleaning products because of excessive house cleaning or misusage of these products to clean foods. Intoxication risk for children from clean products, disinfectants and medications due to passing a long time at home which provides more time to expose these products is also mentioned in this report [30].

Bleach is one of the common household products that contain a range between $3-8 \%$ of sodium hypochlorite and sodium hydroxide. Redness, irritation and tearing are observed by contact of bleach to eyes and vision can be changed as blurry. Mild skin irritation can be observed by dermal contact of bleach to the skin whereas mouth and throat are more resistant to bleach [31]. According to a report about bleach poisoning among children in 2010 , nearly 270,000 children who were under 5 years old were suffered from household products by ingestion and the leading product was bleach as nearly $37 \%$ [31]. The poisoning cases caused by bleach are still increasing in the first two months of 2021 compared to 2020. The 
number of poisoning from bleach is also increased to nearly 600 cases in total January and February 2021 when compared to the same time in 2020. Most affected age groups were reported as $0-5$ years old children and 20-39 years old adults [32]. In addition, medical outcomes of bleach cases consist of mainly minimal clinical effects and about $5 \%$ of moderate effects [33]. [34]. Disinfectant poisoning cases are also increased by nearly 400 cases when compared to the early months of 2020 and the same time in 2021. Cases of 0-5 years old children are reported as approximately 800 cases that is the highest number in all age groups. Nearly 600 cases are reported for 20-39 years old adults and above 300 cases for 40-59 years old middle-aged adults [35]. Although there is a significant increase in disinfectant exposure, when medical outcomes are evaluated, most of them consists of minimal clinical effects and no deaths have been reported according to National Poison Data System (NPDS) [36].

In addition to the reports in the U.S, the Croatian Poison Control Center has also reported several poisonings caused by disinfectants, the frequency has been reported to rise by $100 \%$ when comparing to the same time in 2019, and exposures occur mainly through inhalation or accidental ingestion by adults. According to the reports, poisoning by these routes are reported to be caused no symptoms or led to mild gastrointestinal problems. There were not any occupational cases caused by disinfectant exposure during 2019 in Croatia whereas about 5 cases were reported in 2020 [12]the Croatian Poison Control Centre started receiving phone calls from the general public and healthcare workers, which prompted us to investigate whether the risk of suspected/symptomatic poisonings with disinfectants and sanitisers really increased. To that end we compared their frequency and characteristics in the first half of 2019 and 2020. Cases of exposures to disinfectants doubled in the first half of 2020 (41 vs 21 cases in 2019). Some of responders admitted that they gargle or drink diluted bleach solutions to prevent SARS-CoV-2 and use cleaners or disinfectants to mist their body. In addition, $25 \%$ of volunteers has been reported to suffer from adverse reactions like skin and eye irritation, breathing problems, headache and nausea and they believed that these health problems are caused by cleaners and disinfectants [13]. Aforementioned misusage cases can be considered as important public health problem as well as toxicological key event leading to poisonings and hypersensitivity reactions.
Therefore, publication of recent protocols on effective communication strategies such as "Six Steps for Safe \& Effective Disinfectant Use" and "Safer Cleaning, Sanitizing and Disinfecting during the COVID-19 Pandemic" are published by EPA, CDC and Pediatric Environmental Health Specialty Unit (PEHSU), are believed to increase public knowledge [37-40]

\section{DRUG OR SUBSTANCE ABUSE AND MISUSAGE IN COVID-19 PANDEMIC}

\subsection{Opioids and analgesics}

Substance abuse which includes physical dependence and psychological dependence might be defined as taking an excessive amount of a drug that is detrimental to self and society as well. Physical dependence is observed in conditions that the physical state of an individual with substance use disorder is changed which are also called withdrawal symptoms. Withdrawal symptoms have occurred if the individual who uses the drug for a long time discontinues the drug. Besides, psychological dependence is considered as the need for a drug intensively without physical dependence. [41]. On the other hand, substance misuse is using drugs or substances in an inappropriate way such as alcohol, opioids, and stimulants at very high doses that led to severe health problems. Individuals who have parents often use drugs or substances at home and individuals who have a drug misuse history and genetics are factors that make people more vulnerable to develop substance use disorder. [42]. Approximately 2\% of the world population has substance use disorder and the most vulnerable part of population is people who are younger than 50 years old. [43]. Several reports reveal a significant increase in substance abuse during the COVID-19 pandemic [44-46]. Not only addiction, but also economic burden and social anxiety have been reported to trigger drug abuse during the pandemic. Emotional changes after the pandemic are noticed about in $75 \%$ of respondents that have disruptions or changes in their recovery centers. Respondents mainly reported feelings as worry, fear, sadness and lonely as about $60 \%, 50 \%, 51 \%, 40 \%$, respectively [15].

A report based on the data available on February 2021 revealed that the increase in total overdose deaths due to drug overdose was raised nearly $30 \%$ 
after the declaration of pandemic [47]. In addition, the Overdose Detection Mapping Application Program (ODMAP) released a report to show the impact of COVID-19 on overdose cases and revealed that over $60 \%$ of overdoses increases were after March 2020. The spike alerts were also reported to be increased after stay-at-home orders as nearly $30 \%$ [46]. Among these misused or abused drugs, the opioid drugs and analgesics have been reported to be abused frequently during the lock-down $[44,48,49]$. Opioids such as morphine, hydromorphone, oxymorphone, and methadone are mainly used for analgesia for severe pain that can be classified as cancer-related or non-cancer-related [50]. According to a report available online on 10 July 2020 , overdose cases of opioids are increased after COVID-19 that thought to be due to economic distress and social isolation which increases the risk of relapse. The number of opioid overdose cases between January 14, 2020, and April 26, 2020, in Kentucky emergency medical services (EMS) is evaluated in this study and about $17 \%$ increase is detected overdose cases in EMS and about $50 \%$ increase in cases of overdoses are ended up with death [48]. Another report published on July 2020 showed a link between COVID-19 and drug abuse as about more than $30 \%$ increase in usage of non-prescribed fentanyl according to urine drug test results after the declaration of the pandemic on March 13, 2020 [45]. In addition to the opioid overdose death reports that are collected in more than 30 states, fentanyl group was reported as the main cause of overdose deaths during the pandemic [44]. Moreover, the heroin use was almost doubled, while the methamphetamine use was reported to be increased by approximately 2 percent during pandemic [45]. Ochalek and colleagues (2020) also suggested that the number of visits for nonfatal opioid overdoses have been increased two folds between March and June 2020 compared to the same time in 2019 according to data of one emergency center located in Virginia [44]. Another report by University of Michigan in October 2020 also reported a $15 \%$ increase in opioid overdose since the beginning of pandemic compared to the same time in the previous year. Moreover, naloxone usage was also reported to be elevated about $30 \%$ in the same report, due to the opioid overdose cases compared to the same time in last year [51]. An increase in overdose cases were also detected in Georgia in COVID-19 according to a June 2020 report. Particularly between January and April 2020, about a 3\% increase was identified in the average of weekly overdose reports and the average weekly increase of opioid overdose about $6 \%$ when compared to the previous year. Moreover, the deaths caused by fentanyl-involved overdoses were also reported to be increased about approximately 20\% between December 2019 to April 2020 compared to the records of previous year [52]. The CDC Health Alert Network also mentioned a notable increase in the rates of fatal overdoses across the USA during COVID-19 pandemic, which were mainly due to abuse of synthetic opioids particularly methamphetamine, from March to May 2020 [53].

In addition to the overdose cases of due to opioid abuse, the non-opioid analgesics that are prescribed to relieve chronic and non-cancer pain were also reported as the leading cause of emergency admissions during pandemic. The side effects are listed mainly as constipation, nausea, dry mouth and skin itching [54]. Reported overdose cases caused by non-opioid analgesics in July 2021 in Taiwan evaluated that the mental health problems and financial hardship are the main cause of suicide attempts [55]. Approximately 2,000,000 poisoning cases were responded by US poison control centers according to National Poison Data System in 2019 and above 10\% of them that equals to nearly 280,000 people were caused by analgesics with prescription and non-prescription [56]. In the very first case report about the paracetamol and salicylate overdose on September 8, 2020, it was reported that a man at his late sixties from New York who thought to have a COVID-19 infection, had started a "self-treatment" for his fever and pain by taking aspirin and acetaminophen. The acetaminophen level of 70.8 microgram $(\mathrm{mcg}$ ) per $\mathrm{mL}$ (therapeutic range: $10-30 \mathrm{mcg} / \mathrm{mL}$ ) and a salicylate level of $52.2 \mathrm{mg} / \mathrm{dL}$ (therapeutic range: $0-30 \mathrm{mg} / \mathrm{dL}$ ) in his serum respectively, and the patient was treated in the emergency department by managing serum levels to an acceptable interval for both therapeutics [49]. In November 2020, it was also reported that a 27 -yearold COVID-19 positive woman who had ingested 50 paracetamol tablets to relieve her pain was hospitalized due to excessive vomiting and abdominal pain. The laboratory findings showed acute kidney injury and liver failure and as a result, the patient had liver transplantation [57]. The overall reports have emphasized that treatment or recovery centers for substance users became more difficult in pandemic due to the closure of some healthcare centers and stay-homeorders. According to service feed-back reports, the 
problems in accessing recovery center were experienced by one in three of respondents and nearly $15 \%$ of them cannot receive their needed services $[15,58]$.

\subsection{Alcohol Abuse}

In addition to drug misusage and abuse, ethanol and methanol are the other chemical abused during pandemic regardless of its disinfectant purpose [59-62]. Excessive alcohol intake is an important toxicological concern since it affects target organs such as liver, the kidney, the reproductive system, the pancreas, and mostly the nervous system [63]. The physiological effect of alcohol can be evaluated according to Blood Alcohol Concentration (BAC). When a blood alcohol level reaches $200-300 \mathrm{mg} / \mathrm{dL}$, symptoms of alcohol intoxication are observed like vomiting and incontinence. A blood alcohol level between 400 and $500 \mathrm{mg} / \mathrm{dL}$ becomes potentially fatal and the person may fall into a coma. Values above $500 \mathrm{mg} / \mathrm{dL}$ are very dangerous and can cause death [64]. Abuse of alcohol has a major role due to its availability $[62,65,66]$.

According to the reports, approximately 88,000 deaths have occurred due to excessive alcohol consumption in the US and about $10 \%$ deaths are observed in working-age adults aged between 20 to 64 in the 2020 pandemic, with a third place in preventable deaths in the US [65]. However, there are several reports revealing the main reasons of increase in alcohol intake during the pandemic as stay-home orders and emotional changes such as depression and stress $[59,60]$. In the Canadian population, $\mathrm{Na}$ nos and colleagues (2020) reported that Canadians between 18 and 34 of age have increased their alcohol and cannabis consumption during the pandemic. Besides, about $18 \%$ of Canadians who obey stay-athome orders and currently staying at home reported that they consume more alcohol than that of their before pandemic life. However, Canadians with older ages like 55 years of age are less likely to increase their alcohol consumption which is reported as $10 \%$. On the other hand, alcohol consumption is increased in younger Canadians such as 35 to 54 and 18 to 34 are more than older ages as $25 \%$ and $20 \%$, respectively [59]. Another study revealed the changes in the behavior of alcohol consumption during COVID-19 pandemic reported that binge drinking is increased about 5\% from February to April 2020 in the U.S. among 993 respondents that include 52\% female and $48 \%$ male [67]. In addition to the study of Nanos
(2020) and Barbara (2020), it was indicated that the increase in alcohol consumption about $36 \%$ of participants who are essential workers, older individuals, individuals with children. Individuals having someone with COVID-19 and individuals having higher stress participate in the group that increases their alcohol consumption during pandemic [60]. Another report published in August 2020 mention about 20\% increase in drinking alcohol among active drinkers in the UK and this is linked to financial difficulties, social isolation and stress that is related to the uncertainty of the future due to pandemic, which is related to depression and anxiety during COVID-19 [61]. Another report on the collected data from May 29 to July 14, 2020, indicated that impact of alcohol consumption is associated with depression, anxiety and loneliness due to pandemic [68]. In addition, people who lost their jobs, have eating disorders and have higher depression have increased their alcohol consumption during pandemic compared to the normal population [62].

In addition to alcohol abuse as alcoholic beverages, methanol is also consumed in excessive amounts for different purposes during pandemic regardless of its antiseptic properties [11,69]. Since it is absorbed through the gastrointestinal system, through skin and also by inhalation, $500 \mathrm{mg} / \mathrm{L}$ of methanol concentration in blood is classified as severe methanol toxicity and leads to symptoms such as headache, nausea, vomiting and abdominal pain followed by hyperventilate and dyspnea [70]. The methanol poisoning cases and deaths were reported as eight times higher during the pandemic compared to the same time intervals in 2019 according to the records [69]. Before the pandemic, the main toxicity outbreaks including Estonia, Cambodia, Libya, Czech Republic, Ecuador, Norway, India, Indonesia, Kenya, Nicaragua, Pakistan, Turkey are mentioned in the WHO report on July 2014 and in Iran in 2018 [66,70]. Due to the methanol availability from drugstores such as hand sanitizer had become easier in Iran, the number of poisoning cases were reported to be increased in the pandemic. Moreover, many people believed that drinking or gargling methanol was a way of prevention by COVID-19 infection. According to the reports, Iran was the most affected country due to methanol poisoning during COVID-19 pandemic with above 1,400,000 cases and 5800 deaths, which made Iran $15^{\text {th }}$ place of cumulative poisoning cases among the World according to data of WHO on February 2021 
[49,71]. Another report from Namazi Hospital in Shiraz, Iran was published to mention methanol poisoning cases were reached more than 200 in a week time during pandemic. This report also highlighted the misconception about drinking alcohol-based drinks could be preventive for COVID-19 which caused to increase in cases of methanol poisoning. Moreover, the psychological aspect was assessed in this report as remaining home for a long time might be caused to increase alcohol consumption [72]. According to another report that was reported from Iran suggested that the largest toxic alcohol outbreak was observed in the history of Iran due to COVID-19, which was more than 2500 in a month [11].

\subsection{Illicit Substance Abuse}

In addition to the abuse of analgesics agents, there are several reports revealing the cocaine and cannabis were also abused during pandemic as illicit substances $[45,59]$. The report of the Canadian Centre on Substance Use and Addiction on above a thousand of Canadians between March-April 2020 showed about a $6 \%$ increase in consumption of cannabis and the main reason to increase cannabis consumption were reported as a lack of a regular life schedule, stress, and boredom due to the stay-home regulations during the pandemic [59]. A urine analysis study for the detection of cocaine before and after COVID-19 in the USA revealed a $1.17 \%$ increase in cocaine consumption [45]. A different report published on September 18, 2020, compares urine drug test results for cocaine, heroin, and methamphetamine that were done before the declaration of pandemic and reported that the cocaine abuse was increased in this period from about $3.5 \%$ to $4.7 \%$ [44]. In addition, an important increase in the number of people who take methamphetamine was reported nearly increased $20 \%$ compared to the same interval of previous year [73].

In Table 1, drugs and chemicals abused/ misused during COVID-19 pandemic according to the reports published between 2020- 2021 were given below.

According to a study in our country, Kardaş and colleagues (2020) reported that people feel lonely about $65 \%$ declaration after the COVID-19 pandemic, which indicated that increase of drug use increases about $56 \%$ with the sense of loneliness [16]. In addition to the mentioned study, a letter to the editor from Turkey in May 2020 highlighted those teenagers who are abusing substances during the pandemic are abusing substances to overcome stress. However, abuse of these substances made them vulnerable to stress and trauma, which was reported to an increase

Table 1. Drugs and chemicals abused/ misused during COVID-19 according to the reports between 2020- 2021.

\begin{tabular}{cccc}
\hline Drug/ Chemical & Abuse/ Misusage & Country & Reference \\
\hline Ethanol (hand sanitizer) & Misusage & USA & AAPCC, 2021a \\
Ethanol (hand sanitizer) & Misusage & Croatia & Ž. Babić et al., 2020 \\
Bleach & Misusage & USA & AAPCC, 2021b \\
Methamphetamine & Abuse & USA & CDC Health Alert Network, 2020 \\
Fentanyl & Abuse & USA (Virginia) & Ochalek et al., 2020a \\
Heroin & Abuse & USA & Governor, 2020 \\
Cocaine & Abuse & USA & Wainwright et al., 2020 \\
Cannabis & Abuse & Canada & CCSA, 2020 \\
Alcohol (beverage) & Abuse & Canada & CCSA, 2020 \\
Alcohol (beverage) & Abuse & UK & Iran \\
Methanol (beverage) & Misusage & USA & Rouphael et al., 2020
\end{tabular}




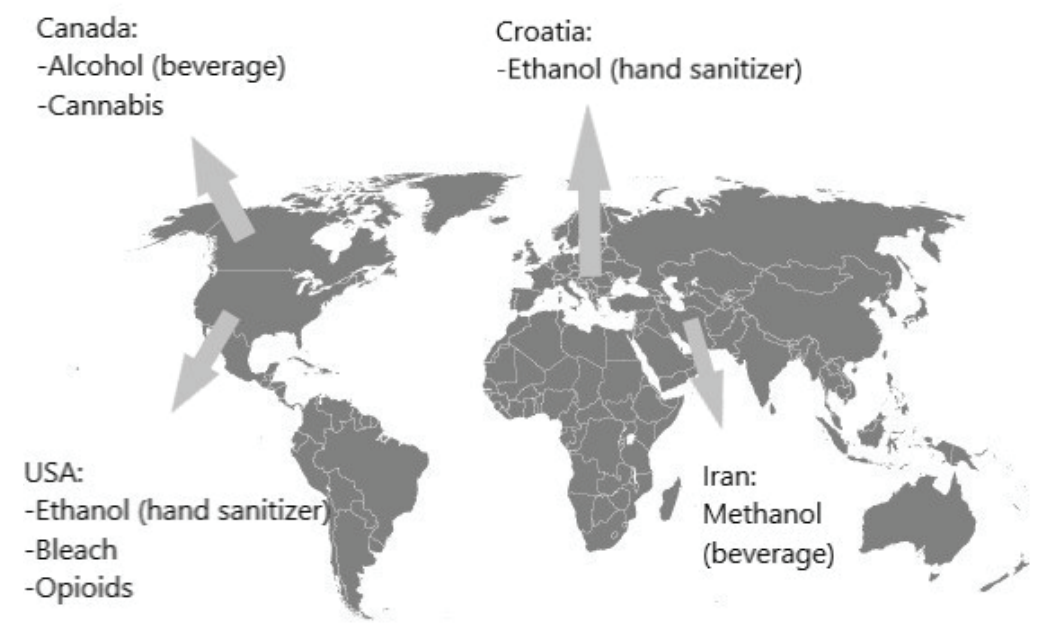

Figure 1. Drugs and chemicals abused/ misused during COVID-19 according to the reports between 2020-2021 $[12,32,44,45,59,69]$

in the substance craving and frequency of drug use [17]. In Figure 1, abused and misused substances were depicted based on the emergency and healthcare center reports between 2020- mid 2021.

\section{CONCLUSION}

The pandemic has unexpectedly increased the tendency towards many disease-preventing chemicals or drugs, especially disinfectants, in each age group all over the world. In addition to poisoning and hypersensitivity reactions due to incorrect or excessive use of these substances, it has been observed that the tendency of people who abuse certain substances in pandemic has been increased. Hence, the management of substance abuse and misusage plays an important role in pandemic to prevent toxicological events. In addition, the correct management of the process is valuable for the sociological management of public health during pandemic. In particular, regular pharmacovigilance reporting by hospitals, pharmacies and poison reporting centers will be thought to contribute to the formation of protocols for raising public awareness and the formation of public health awareness by managing the process correctly.

\section{REFERENCES}

1. Rauf, A., Abu-Izneid, T., Olatunde, A., Ahmed Khalil, A., Alhumaydhi, F.A., Tufail, T., Shariati, M.A., Rebezov, M., Almarhoon, Z.M., Mabkhot, Y.N., Alsayari, A., and Rengasamy,
K.R.R. (2020) COVID-19 Pandemic: Epidemiology, Etiology, Conventional and Non-Conventional Therapies. Int. J. Environ. Res. Public Health, 17 (21), 8155.

2. Wu, D., Wu, T., Liu, Q., and Yang, Z. (2020) The SARSCoV-2 outbreak: What we know. International Journal of Infectious Diseases, 94, 44-48.

3. Abdul-Rasool, S., and Fielding, B.C. (2010) Understanding Human Coronavirus HCoV-NL63. Open Virol. J., 4, 76-84.

4. Shereen, M.A., Khan, S., Kazmi, A., Bashir, N., and Siddique, R. (2020) COVID-19 infection: Origin, transmission, and characteristics of human coronaviruses. J. Adv. Res., 24, 91-98.

5. Anderson, E.L., Turnham, P., Griffin, J.R., and Clarke, C.C. (2020) Consideration of the Aerosol Transmission for COVID-19 and Public Health. Risk Anal., 40 (5), 902-907.

6. World Health Organization, (WHO) (2021) WHO COVID-19 Dashboard Advices.; 2021 January 30. Available from: https:// www.who.int/emergencies/diseases/novel-coronavirus-2019/ advice-for-public. [Website]

7. FDA approval of remdesivir.; 2021 January 30. Available from: https://www.fda.gov/drugs/drug-safety-and-availability/ fdas-approval-veklury-remdesivir-treatment-covid-19science-safety-and-effectiveness [Website]

8. Republic of Turkey Ministry of Health Republic of Turkey Ministry of Health-COVID-19 Information 2021 January 30. Available from: https://covid19.saglik.gov.tr/TR-66299/covid19-tedavi.html [Website]

9. World Health Organization, (WHO) 2021 January 26. Draft Landscape and Tracker of COVID-19 candidate vaccines.; Available from: https://www.who.int/publications $/ \mathrm{m} /$ item/ draft-landscape-of-covid-19-candidate-vaccines [Website] 
10. Centers for Disease Control and Prevention CDC COVID-19 Vaccines.; 2021 January 21. Available from: https://www.cdc. gov/coronavirus/2019-ncov/vaccines/different-vaccines.html [Website]

11. Arasteh, P., Pakfetrat, M., and Roozbeh, J. (2020) A Surge in Methanol Poisoning Amid COVID-19 Pandemic: Why Is This Occurring? Am. J. Med. Sci., 360 (2), 201.

12. Babić, Å., Turk, R., and MacAn, J. (2020) Toxicological aspects of increased use of surface and hand disinfectants in Croatia during the COVID-19 pandemic: A preliminary report. Arh. Hig. Rada Toksikol., 71 (3), 261-264.

13. Gharpure, R., Hunter, C.M., Schnall, A.H., Barrett, C.E., Kirby, A.E., Kunz, J., Berling, K., Mercante, J.W., Murphy, J.L., and Garcia-Williams, A.G. (2020) Knowledge and practices regarding safe household cleaning and disinfection for COVID-19 prevention - United States, May 2020. Am. J. Transplant., 20 (10), 2946-2950.

14. Rosenman, K.D., Reilly, M.J., and Wang, L. (2020) Calls to a State Poison Center Concerning Cleaners and Disinfectants from the Onset of the COVID-19 Pandemic Through April 2020. Public Health Rep. 36(1):27-31.

15. Hulsey, J., Mellis, A., and Kelly, B. 2020 September 10. COVID-19 Pandemic Impact on Patients, Families \& Individuals in Recovery from a SUD. Addict. Policy Forum. Available from: https://www.addictionpolicy.org/post/covid19-pandemic-impact-on-patients-families-individuals-inrecovery-fromsubstance-use-disorder [Website]

16. Horigian, V.E., Schmidt, R.D., and Feaster, D.J. (2020) Loneliness, Mental Health, and Substance Use among US Young Adults during COVID-19. J. Psychoactive Drugs, 1 (4), 1-9.

17. Kardaş, Ö. (2020) Adolescent with substance abuse disorder during the COVID-19 pandemic (tur). J. Clin. Psychiatry, 103-104.

18. PubChem (2021) Ethanol (Compound Summary); 2021 February 12. Available from: https://pubchem.ncbi.nlm.nih.gov/ compound/Ethanol [Website].

19. Le Daré, B., Lagente, V., and Gicquel, T. (2019) Ethanol and its metabolites: update on toxicity, benefits, and focus on immunomodulatory effects. Drug Metab. Rev., 51 (4), 545-561.

20. LaHood AJ, Kok SJ. Ethanol Toxicity. 2021 Mar 28. In: StatPearls [Internet]. Treasure Island (FL): StatPearls Publishing; Available from: https://www.ncbi.nlm.nih.gov/books/ NBK557381 [Website].

21. Mahmood, A., Eqan, M., Pervez, S., Alghamdi, H.A., Tabinda, A.B., Yasar, A., Brindhadevi, K., and Pugazhendhi, A. (2020) COVID-19 and frequent use of hand sanitizers; human health and environmental hazards by exposure pathways. Sci. Total Environ., 742, 140561.
22. AAPCC (2021) AAPCC-Hand Santisizer.; 2021 February 12. Available from: https://piper.filecamp.com/s/iUQdglO4bCOySuY8/fi [Website]

23. Chang, A., Schnall, A.H., Law, R., Bronstein, A.C., Marraffa, J.M., Spiller, H.A., Hays, H.L., Funk, A.R., Mercurio-Zappala, M., Calello, D.P., Aleguas, A., Borys, D.J., Boehmer, T., and Svendsen, E. (2020) Cleaning and Disinfectant Chemical Exposures and Temporal Associations with COVID-19 - National Poison Data System, United States, January 1, 2020March 31, 2020. MMWR. Morb. Mortal. Wkly. Rep., 69 (16), 496-498.

24. EPA (2021) What's the difference between products that disinfect, sanitize, and clean surfaces? Available from: https://www. epa.gov/coronavirus/whats-difference-between-productsdisinfect-sanitize-and-clean-surfaces [Website].

25. CDC (2019) Keeping Hands Clean. Available from: https:// www.cdc.gov/healthywater/hygiene/hand/handwashing.html [Website].

26. World Health Organization, (WHO) 2020 May 7. Cleaning and Disinfection of Environmental Surfaces in the context of COVID-19: Interim guidance. Available from: https://www.who. int/publications-detail-redirect/cleaning-and-disinfection-ofenvironmental-surfaces-inthe-context-of-covid-19 Website].

27. Zheng, G., Filippelli, G.M., and Salamova, A. (2020) Increased Indoor Exposure to Commonly Used Disinfectants during the COVID-19 Pandemic. Environ. Sci. Technol. Lett., 7 (10), $760-765$.

28. Cates, A.L., and Krueger, J. (2020) 103 Impact of Stay-atHome Orders on Reported Pediatric Poisonings during the COVID-19 Pandemic. Ann. Emerg. Med., 76 (4), S40-S41.

29. Le Roux, G., Sinno-Tellier, S., Puskarczyk, E., Labadie, M., von Fabeck, K., Pélissier, F., Nisse, P., Paret, N., Descatha, A., Vodovar, D., Tournoud, C., Langrand, J., Laborde-Casterot, H., Car, W., Franchitto, N., Simon, N., de Haro, L., Paradis, C., Nardon, A., Patat, A.M., Deguigne, M., Legeay, M., and Azzouz, R. (2021) Poisoning during the COVID-19 outbreak and lockdown: retrospective analysis of exposures reported to French poison control centres. Clin. Toxicol., 59 (9), 832-839.

30. Le Roux, G., Sinno-Tellier, S., and Descatha, A. (2020) COVID-19: home poisoning throughout the containment period. Lancet Public Heal., 5 (6), 314.

31. Benzoni, T. (2020) Bleach Toxicity.; 2021 February 12. Available from: https://www.ncbi.nlm.nih.gov/books/ NBK441921/\#_NBK441921_pubdet [Website]

32. AAPCC (2021) AAPCC Bleach.; 2021 February 12. Available from: https://piper.filecamp.com/s/2JOgZWDh1BpP4tQz/fi. [Website] 
33. AAPCC (2021) National Poison Data System (NPDS) Bulletin COVID-19 (Bleach). Report Available from : https://piper. filecamp.com/uniq/Y81efVeQNil4mNRp.pdf [Website]

34. AAPCC (2021) AAPCC Hand Sanitizer 2021.; 2021 February 12. Available from: https://aapcc.org/track/hand-sanitizer. [Website]

31. AAPCC (2021) AAPCC Disinfectants.; 2021 February 12. Available from: https://piper.filecamp.com/s/UFJg0SeSNxCbMb4j/fi. [Website]

36. AAPCC (2021) National Poison Data System (NPDS) Bulletin COVID-19 (Disinfectant) Report Available from: https:// piper.filecamp.com/uniq/Y81efVeQNil4mNRp.pdf [Website]

37. EPA (2020) 6 Steps for Safe \& Effective Disinfectant Use.; 2021 June 14. Available from: https://www.epa.gov/sites/production/files/2020-04/documents/disinfectants-onepager.pdf [Website]

38. PEHSU (2020) Safer Cleaning, Sanitizing and Disinfecting during the COVID-19 Pandemic.; 2021 June 14. Available from: https://www.epa.gov/sites/production/files/2020-11/documents/leonard_r9asktheexperts_508c_english.pdf [Website]

39. Gharpure, R., Miller, G.F., Hunter, C.M., Schnall, A.H., Kunz, J., and Garcia-Williams, A.G. (2021) Safe use and storage of cleaners, disinfectants, and hand sanitizers: Knowledge, attitudes, and practices among U.S. adults during the COVID-19 pandemic, May 2020. Am. J. Trop. Med. Hyg., 104 (2), 496501.

40. CDC (2020) Six Steps for Properly Cleaning and Disinfecting Your School.

41. Griffin, J.B. (1990) Substance Abuse, in Clinical Methods: The History,Physical, and Laboratory Examinations, 3ed., Butterworths, Boston.

42. McLellan, A.T. (2017) Substance Misuse and Substance use Disorders: Why do they Matter in Healthcare? Trans. Am. Clin. Climatol. Assoc., 128, 112-130.

43. Our World in Data (2017) substance use disorders.; 2021 February 27. Available from: https://ourworldindata.org/druguse\#prevalence-of-substance-use-disorders. [Website]

44. Ochalek, T.A., Cumpston, K.L., Wills, B.K., Gal, T.S., and Moeller, F.G. (2020) Nonfatal Opioid Overdoses at an Urban Emergency Department During the COVID-19 Pandemic. JAMA, 324 (16), 1673.

45. Wainwright, J.J., Mikre, M., Whitley, P., Dawson, E., Huskey, A., Lukowiak, A., and Giroir, B.P. (2020) Analysis of Drug Test Results Before and After the US Declaration of a National Emergency Concerning the COVID-19 Outbreak. JAMA, 324 (16), 1674

46. Alter, A., and Yeager, C. (2020) COVID-19 Impact on US National Overdose Crisis. (March), 1-5. Available from: http://
www.odmap.org/Content/docs/news/2020/ODMAP-ReportJune-2020.pdf [Website]

47. CDC (2021) Provisional Drug Overdose Death Counts.; 2021 Febuary 15. Available from: https://www.cdc.gov/nchs/nvss/ vsrr/drug-overdose-data.htm\#notes. [Website]

48. Slavova, S., Rock, P., Bush, H.M., Quesinberry, D., and Walsh, S.L. (2020) Signal of increased opioid overdose during COVID-19 from emergency medical services data. Drug Alcohol Depend., 214 (January), 108176.

49. Wen, T., Chu, J., Allenspach, D., and Van, D. (2020) Delirium Associated with Salicylate and Acetaminophen Overdose in a Patient with COVID-19: A Case Report. Clin. Pract. Cases Emerg. Med., 4 (4), 517-520.

50. Overholser, B.R., and Foster, D.R. (2011) Opioid pharmacokinetic drug-drug interactions. Am. J. Manag. Care, 17 (1), 276-287.

51. Gavin (2020) Real-Time Overdose Tracking Helps Show COVID-19's Effects.

52. Governor (2020) Suspected Drug Overdose Increases in Georgia Amid COVID-19.

53. CDC Health Alert Network (2020) Increase in Fatal Drug Overdoses Across the United States Driven by Synthetic Opioids Before and During the COVID-19 Pandemic.

54. Arthritis Foundation (2020) Analgesics.; 2021 February 27. Available from: https://www.arthritis.org/drug-guide/analgesics/analgesics\#: :text=Analgesics are a class of,are only available by prescription. [Website]

55. Tan, S.-T., Chen, T.-H., Yang, H.-W., and Su, Y.-J. (2021) Changes in poisoning during the COVID-19 pandemic worldwide. Am. J. Emerg. Med., (January).

56. AAPCC (2019) APCC Dashboard 2019.; 2021 February 21. Available from: https://aapcc.org/national-poison-data-system. [Website]

57. Rouphael, C., D’Amico, G., Ricci, K., Cywinski, J., Miranda, C., Koval, C., Duggal, A., Quintini, C., Menon, K.V.N., Miller, C., and Modaresi Esfeh, J. (2020) Successful orthotopic liver transplantation in a patient with a positive SARS-CoV2 test and acute liver failure secondary to acetaminophen overdose. Am. J. Transplant., 2 (5763), ajt.16330.

58. Corallo (2020) Impact of Coronavirus on Community Health Centers.; 2021 February 15. Available from: https://www.kff. org/coronavirus-covid-19/issue-brief/impact-of-coronaviruson-community-health-centers/. [Website]

59. CCSA (2020) 25\% of Canadians (aged 35-54) are drinking more while at home due to COVID-19 pandemic; cite lack of regular schedule, stress and boredom as main factors. (April).

60. Sallie, S.N., Ritou, V., Bowden-Jones, H., and Voon, V. (2020) Assessing international alcohol consumption patterns during 
isolation from the COVID-19 pandemic using an online survey: Highlighting negative emotionality mechanisms. BMJ Open, 10 (11), 1-10.

61. Kim, J.U., Majid, A., Judge, R., Crook, P., Nathwani, R., Selvapatt, N., Lovendoski, J., Manousou, P., Thursz, M., Dhar, A., Lewis, H., Vergis, N., and Lemoine, M. (2020) Effect of COVID-19 lockdown on alcohol consumption in patients with pre-existing alcohol use disorder. Lancet Gastroenterol. Hepatol., 5 (10), 886-887.

62. Sugarman, D.E., and Greenfield, S.F. (2021) Alcohol and COVID-19: How Do We Respond to This Growing Public Health Crisis? J. Gen. Intern. Med., 36 (1), 214-215.

63. Ivan Rusyn, R.B. (2008) Alcohol and Toxicity. J. Hepatol., 6 (9), 2166-2171.

64. Dasgupta, A. (2017) Alcohol a double-edged sword, in Alcohol, Drugs, Genes and the Clinical Laboratory, Elsevier, pp. $1-21$.

65. MDHHS (2020) Alcohol Use and COVID-19.; 2021 February 23. Available from: https://www.michigan.gov/documents/mdhhs/MDHHS_Fact_Sheet_-_Alcohol_and_COVID-19_692941_7.pdf. [Website]

66. Aghababaeian, H., Ahvazi, L.A., and Ostadtaghizadeh, A. (2019) The methanol poisoning outbreaks in Iran 2018. Alcohol Alcohol., 54 (2), 128-130.

67. Barbosa (2020) How Has Drinking Behavior Changed During the COVID-19 Pandemic? 2021 February 23. Available from: https://www.apa.org/members/content/barbosa-alcohol-usecovid-19-slides.pdf. [Website]
68. CIHR (2020) Alcohol consumption and the COVID-19 pandemic: synthesizing knowledge for policy action.

69. Shokoohi, M., Nasiri, N., Sharifi, H., Baral, S., and Stranges, S. (2020) A syndemic of COVID-19 and methanol poisoning in Iran: Time for Iran to consider alcohol use as a public health challenge? Alcohol, 87 (January), 25-27.

70. World Health Organization, (WHO) (2014) Information note of Methanol. (September). Available from: https://www.who. int/environmental_health_emergencies/poisoning/methanol_ information.pdf. [Website]

71. World Health Organization, (WHO) (2021) WHO COVID-19 Dashboard-Iran.; 2021 February 11. Available from: https:// covid19.who.int/region/emro/country/ir. [Website]

72. Mousavi-Roknabadi, R. S., Arzhangzadeh, M., Safaei-Firouzabadi, H., Mousavi-Roknabadi, R. S., Sharifi, M., Fathi, N., Zarei Jelyani, N., \& Mokdad, M. (2021). Methanol poisoning during COVID-19 pandemic; A systematic scoping review. The American journal of emergency medicine, 52, 69-84.

73. Hedegaard, H., Miniño, A.M., and Warner, M. (2020) Drug Overdose Deaths in the United States, 1999-2018. NCHS Data Brief, (356), 1-8. 